\title{
Tuning the Hierarchical Structure and Resilience of Resilin-like Polypeptide Hydrogels Using Graphene Oxide
}

Balu, Rajkamal; Dorishetty, Pramod; Mata, Jitendra; Hill, Anita; Dutta, Naba; Roy Choudhury, Namita https://researchrepository.rmit.edu.au/esploro/outputs/9921970151901341/filesAndLinks?institution=61RMIT_INST\&index=null

Balu, R., Dorishetty, P., Mata, J., Hill, A., Dutta, N., \& Roy Choudhury, N. (2020). Tuning the Hierarchical Structure and Resilience of Resilin-like Polypeptide Hydrogels Using Graphene Oxide. ACS Applied Bio Materials, 3(12), 8688-8697. https://doi.org/10.1021/acsabm.0c01088

Document Version: Accepted Manuscript

Published Version: https://doi.org/10.1021/acsabm.0c01088

Repository homepage: https://researchrepository.rmit.edu.au

(c) 2020 American Chemical Society

Downloaded On 2023/04/26 22:19:30 +1000 


\section{Tuning the Hierarchical Structure and Resilience of Resilin-Like Polypeptide Hydrogels using Graphene Oxide}

Rajkamal Balu, ${ }^{\text {a }}$ Pramod Dorishetty, ${ }^{\mathrm{a}}$ Jitendra P. Mata, ${ }^{\mathrm{b}}$ Anita J. Hill, ${ }^{\mathrm{c}}$ Naba K. Dutta, ${ }^{* a}$ Namita R. Choudhury*a

${ }^{a}$ Chemical and Environmental engineering, School of Engineering, RMIT University, Melbourne, VIC 3000, Australia

${ }^{b}$ Australian Centre for Neutron Scattering (ACNS), Australian Nuclear Science and Technology Organisation (ANSTO), Lucas Heights, NSW 2232, Australia

${ }^{c}$ Commonwealth Scientific and Industrial Research Organisation (CSIRO) Manufacturing, Clayton, VIC 3168, Australia

*Corresponding author E-mail: naba.dutta@rmit.edu.au; namita.choudhury@rmit.edu.au 


\begin{abstract}
Resilin-like polypeptides (RLPs) are an important class of intrinsically disordered multi stimuli-responsive bioelastomers. The nanostructure of RLPs in solution has been extensively studied in the past few years, from dilute to molecular crowding conditions, and with the addition of rigid biopolymers. Modification of the hierarchical network structure of RLP hydrogels using graphene oxide (GO) as an additive is a burgeoning prospect for their application in the bioelectronics and biomedical fields. In this work, we systemically study the influence of incorporating GO into RLP (Rec1) hydrogels for tuning their physicochemical properties and understanding gel-cell interactions. The nature of the GO interaction with the Rec1 hydrogel is deduced from the change in structure and properties. Contrast matching small-angle and ultra-small-angle neutron scattering techniques were used to investigate the network structure of the Rec1 hydrogel and how this structure is modified in the presence of GO. Incorporation of GO in the Rec1 hydrogel matrix results in an increase in micromechanical resilience, equilibrium water swelling ratio, micropore size, crosslinked domain size; with a decrease in crosslink density, mass fractal cluster size, local compressive elastic modulus, and cell inert characteristics. These property combinations achieved with the addition of GO, further open up the available structure property design window for RLP applications.
\end{abstract}

Keywords: resilin, graphene oxide, hybrid hydrogels, small-angle neutron scattering, micromechanical properties, cell culture 


\section{INTRODUCTION}

Hydrogels are three-dimensional (3D) networks of crosslinked polymer molecules with high water sorption capacity. Peptide and protein-based hydrogels are used as matrices for drug delivery and tissue engineering, owing to their excellent biocompatibility and biodegradability. ${ }^{1}$ Natural resilin is the most efficient elastomeric protein known to date, which exists as di- and tri-tyrosine crosslinked hydrogels, that enables many insects to jump and fly. ${ }^{2}$ Genetically engineered resilin, or resilin-like polypeptide (RLP)-based hydrogels have gained increasing research interest and application due to their outstanding tensile resilience, stimuliresponsiveness, and multi-functional properties. ${ }^{3}$ In 2005 , Elvin et al. ${ }^{4}$ expressed the first RLP, namely Rec1 encoding exon-1 of the fruit fly (Drosophila melanogaster) gene product CG15920 in the bacteria Escherichia coli using recombinant technology. The water soluble Rec1 comprises 18 copies of the amino acid sequence GGRPSDSYGAPGGGN with a molecular weight of $28.5 \mathrm{kDa}{ }^{4}$ Subsequently, several other RLPs of varying molecular weight and amino acid sequence have been synthesized and crosslinked (using different methods) to form hydrogels, which exhibit resilience values from $85-100 \%$ as measured by scanning probe microscopy, surpassing that of natural elastin hydrogel $(90 \%)$ and synthetic polybutadiene rubber $(80 \%) .{ }^{4}$ These RLP hydrogels have been evaluated for their potential use in drug delivery and tissue engineering applications in the biomedical field. ${ }^{5,6}$

Over the past decade, we have extensively studied the structure property relationships of RLPs, from dilute to concentrated aqueous solutions, and have revealed their intrinsically disordered protein (IDP) structure and multi-stimuli responsive properties, including uncommon dual-phase thermal transition behaviour (i.e. exhibiting both upper and lower critical solution temperature). ${ }^{7-10}$ Furthermore, we have also demonstrated fabrication of organized nanostructures, ${ }^{11} \mathrm{pH}$-responsive interfaces, ${ }^{12}$ photocrosslinked hydrogels, ${ }^{13}$ and exploitation of these multi-functional soft templates to generate size and physical property 
control over metal nano-clusters/particles using Rec1. ${ }^{14-19}$ The effect of crowding and the addition of rigid biopolymers to RLPs, such as regenerated silk fibroin (SF) protein and polyL-proline polypeptide, on the nanostructure of RLPs in solution has been reported. ${ }^{10,20}$ Cocrosslinking Rec1 with rigid SF protein molecules showed improvements in the tensile storage modulus of RLP-based hydrogels. ${ }^{21}$ However, the hierarchical (nano- to microscale) network structure of RLPs in the presence of carbon allotrope additives, such as graphene oxide (GO) in hydrogels has not been investigated. ${ }^{22}$ In addition to hierarchical structure, micromechanical properties and gel-cell interactions are essential for cellular communication. ${ }^{23,24}$ Therefore, the present work studies the effect of GO on structure property relationships and gel-cell interactions for RLP-based hydrogels.

GO is a functionalized monomolecular layer of graphite with a large specific surface area, water solubility, chemical functionality, high mechanical strength, nonspecific interaction with peptides and proteins, and reported to promote cell attachment and/or proliferation. ${ }^{25-27}$ Moreover, incorporation of GO into protein hydrogels has been shown to significantly influence their physicochemical properties. ${ }^{22,28}$ In this work, GO is chosen as a promising material with an aim to tune the physicochemical properties, such as water uptake, crosslink density, hierarchical structure, micromechanical properties, and biological activity, and to investigate the hierarchical structure of Rec1/GO hybrid hydrogels. Rec1/GO hybrid hydrogels were fabricated at a Rec1-concentration of $20 \mathrm{wt} \%$ (minimum concentration required for forming crosslinked hydrogel network) with GO content varying in the range of $0.02-0.2 \mathrm{wt} \%$ (Table 1) via a ruthenium-mediated photocrosslinking method. ${ }^{28}$ The maximum GO content used in Rec1/GO hybrid hydrogels was $0.2 \mathrm{wt} \%$, as beyond this concentration GO forms an inhomogeneous dispersion (partially precipitates/aggregates) in $20 \mathrm{wt} \% \mathrm{Rec} 1$ solution. The hybrid hydrogels were investigated using water uptake, scanning electron microscopy (SEM), small-angle neutron scattering (SANS), ultra-small-angle neutron scattering (USANS), 
Fourier-transform infrared (FTIR) spectroscopy, differential scanning calorimetry (DSC), micro-indentation, and gel-cell interaction (using mouse fibroblast cells).

\section{EXPERIMENTAL SECTION}

Materials: GO $(0.4 \mathrm{wt} \%$ dispersion in water, particle size $<4 \mu \mathrm{m})$ was procured from Graphenea Inc., USA. Ammonium persulfate (APS), and tris(2,2-bipyridyl)dichlororuthenium(II)hexahydrate (Ru-bpy) were procured from Sigma-Aldrich, Australia. The L929 mouse fibroblast cell line was kindly provided by the RMIT Micro Nano Research Facility. Deuterium oxide $\left(\mathrm{D}_{2} \mathrm{O}\right)$ was kindly provided by ANSTO. Penicillin-streptomycin (PS), fetal bovine serum (FBS), and Dulbecco's modified Eagle's medium GlutaMax (DMEMGX) were procured from Life Technologies, USA. Paraformaldehyde, sodium cacodylate buffer and osmium tetroxide were procured from ProSciTech Pty. Ltd., Australia.

Synthesis and purification of Rec1: Rec1 was synthesized as reported by Kim et al. ${ }^{29}$ Briefly, the exon-1 of gene product CG15920 was cloned and expressed (lactose induced fermentation with primary induction) in $E$. coli with an obtained protein yield of $\sim 300 \mathrm{mg} / \mathrm{L}$ of culture. The expressed protein was then extracted by cell lysis, and purified by a non-chromatographic method of salting out and heat denaturation. ${ }^{29}$ The denatured protein molecules were then removed by centrifugation $(15 \mathrm{~min})$ of the resulting solution at $12,000 \mathrm{~g}$. The obtained supernatant was cooled, in order to get $\sim 25 \mathrm{wt} \%$ of Rec1 in the lower liquid phase by coacervation, and stored at $-20{ }^{\circ} \mathrm{C}$.

Fabrication of hydrogels: For Rec1 hydrogel fabrication, predefined volumes of aqueous Rubpy and APS solutions were added to a predefined volume of Rec1 stock solution and stirred for $5 \mathrm{~min}$. The obtained mixture was cast in a Teflon mold, exposed for 2 min to LED white light $(50 \mathrm{~W})$ to initiate crosslinking (Figure 1), removed from the mold and turned over for further exposure to white light for $30 \mathrm{sec}$. For fabrication of Rec1/GO hybrid hydrogels, a 
predefined volume of GO stock dispersion was added dropwise (under bath sonication) to a predefined volume of Rec1 stock solution. The Rec1/GO mixture was then gently stirred (15 min) using a magnetic stirrer followed by ultrasonication (on an ice bath) for 5 min (in short intervals) using a Qsonica Q125 sonicator (20\% amplitude). Subsequently, predefined volumes of aqueous Ru-bpy and APS solutions were added to the obtained Rec1/GO mixture and further stirred for $5 \mathrm{~min}$. The mixtures were then crosslinked as described for Rec1 hydrogel fabrication. The final concentration of Rec1 in the crosslinking mixtures was $20 \mathrm{wt} \%$; whereas, Ru-bpy and APS were $5 \mathrm{mM}$ and $28 \mathrm{mM}$, respectively. The crosslinked hydrogels were subsequently dialyzed (to remove excess reactants) with Milli-Q water for 24 hours.
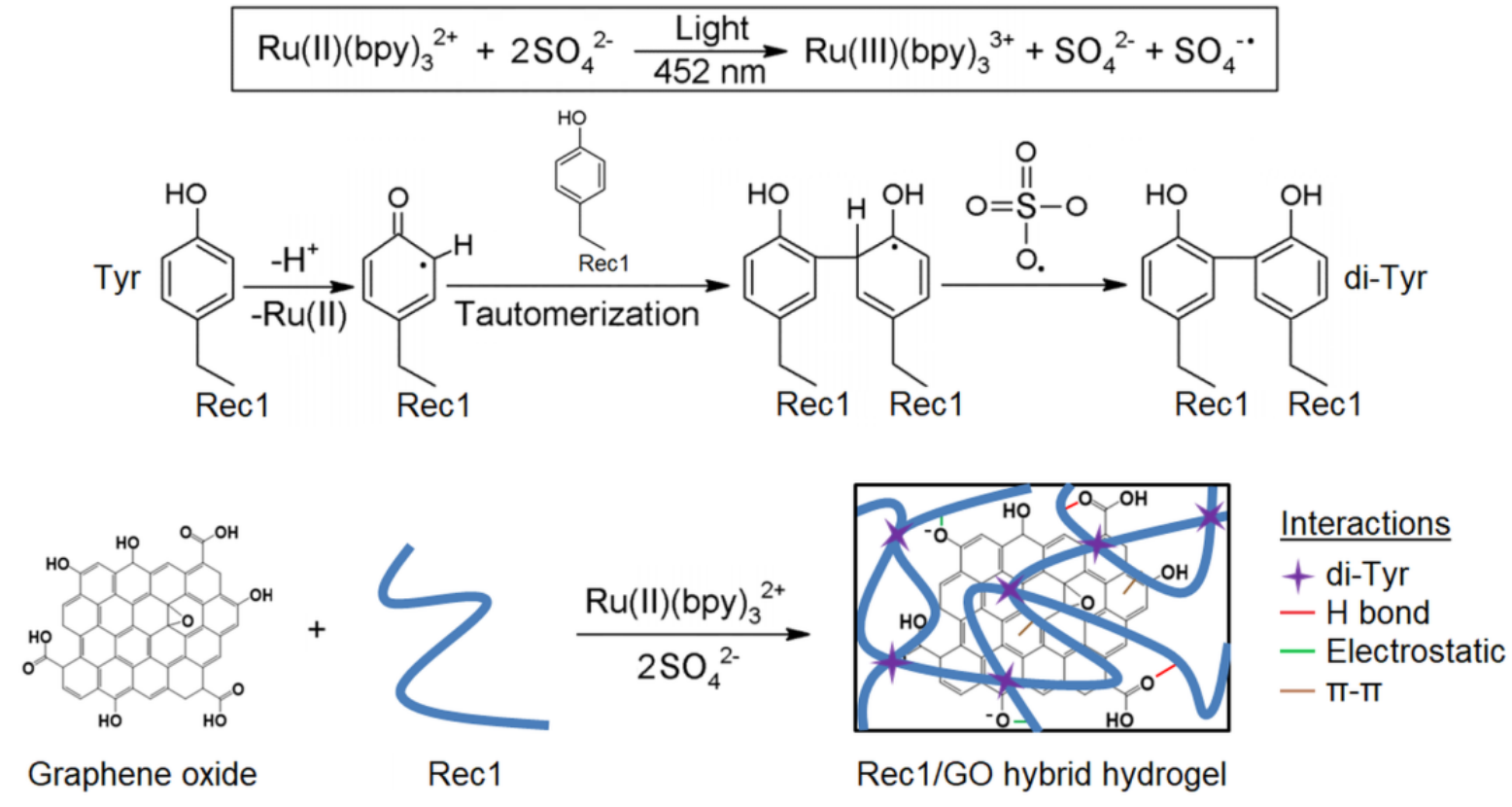

Figure 1. Mechanism of crosslinking reaction of the fabricated hydrogels.

Characterization: The water swelling ratio $\left(\mathrm{W}_{\mathrm{s}} / \mathrm{W}_{\mathrm{d}}\right.$; where $\mathrm{W}_{\mathrm{s}}$ and $\mathrm{W}_{\mathrm{d}}$ are the equilibrium swollen and dry weight, respectively) and the crosslink density of fabricated hydrogels were calculated using equations 1 and $2 .^{28}$

$$
v_{1, s}=\frac{\frac{W_{d}}{\rho_{d}}}{\frac{W_{s}-W_{d}}{\rho_{2}}+\frac{W_{d}}{\rho_{d}}}
$$




$$
\text { Crosslink density }=\frac{-\ln \left(1-v_{1, s}\right)+v_{1, s}+X v_{1, s}}{V_{2}\left[v_{1, s}-\frac{1}{2} v_{1, s}\right]}
$$

where $\rho_{\mathrm{d}}$ is the density of the dehydrated hydrogel $\left(1.3 \mathrm{~g} / \mathrm{cm}^{3}\right)^{13}, \rho_{2}$ is the density of water $\left(0.997 \mathrm{~g} / \mathrm{cm}^{3}\right), v_{1, \mathrm{~s}}$ is the volume fraction of the hydrogel in the equilibrium swollen state, $X$ is the Flory-Huggins interaction parameter between the polypeptide and water $(0.48)$, and $\mathrm{V}_{2}$ is the molar volume of water $\left(18 \mathrm{~cm}^{3} / \mathrm{mol}\right) .{ }^{28}$ Experiments were performed in triplicate and the data are reported (Table 1) as the mean with population standard deviation.

The microstructure of equilibrium water swollen and freeze-dried (fracture surface) hydrogels, and the morphology of L929 fibroblast cells cultured (details given below) on hydrogel surfaces were observed using a Philips XL30 Field Emission SEM (with $10 \mathrm{kV}$ accelerating voltage). The average pore sizes and standard deviations were obtained using the ImageJ software package. All samples were platinum sputter-coated for analysis. The hierarchical network structure of equilibrium $\mathrm{D}_{2} \mathrm{O}$ swollen Rec1 and Rec1/GO3 hybrid hydrogels was analyzed using the Quokka SANS and Kookaburra USANS instruments at ANSTO. ${ }^{30-31}$ Hydrogels were loaded into custom-built sample holders, along with excess $\mathrm{D}_{2} \mathrm{O}$, and used for both SANS and USANS measurements at $25^{\circ} \mathrm{C}$. Neutron wavelengths of $5 \AA^{-1}$ and $8.1 \AA^{-1}$ (for lens optics) and source aperture to sample aperture distances of 20, 12, and 2 m were used for SANS measurements (q-range of $0.0007-0.3 \AA^{-1}$ where $\mathrm{q}$ is the scattering vector as given in equation 3$)^{32}$, whereas a neutron wavelength of $4.74 \AA^{-1}$ was used for USANS measurements (q-range of $0.00004-0.001 \AA^{-1}$ ).

$$
q=\frac{4 \pi \sin (\theta)}{\lambda}
$$

where $2 \theta$ is the scattering angle and $\lambda$ is the neutron wavelength. The obtained SANS and USANS data were processed as reported in our previous publications. ${ }^{33-35}$ The structural parameters were estimated using appropriate model function fits in the SasView software. 
The chemical fingerprints of the freeze-dried hydrogels were analyzed over the wavenumber range $4000-700 \mathrm{~cm}^{-1}$ using a Perkin Elmer Frontier FTIR spectrometer with ATR accessory. The glass transition temperature of the freeze-dried hydrogels was measured over the range $25-250{ }^{\circ} \mathrm{C}$ using a TA Instrument Q2000 DSC. The measurements were made using samples sealed in Tzero hermetic aluminum pans with a heating rate of $10{ }^{\circ} \mathrm{C} / \mathrm{min}$ and a nitrogen flow rate of $50 \mathrm{~mL} / \mathrm{min}$.

The micromechanical properties of fabricated hydrogels (submerged in Milli-Q water) were evaluated using a Bose ElectroForce 5500 test instrument with a $250 \mathrm{~g}$ load cell. The force versus displacement measurements were performed at a rate of $0.1 \mathrm{~mm} / \mathrm{s}$ using a $1 \mathrm{~mm}$ diameter cylindrical probe. The experimental stress was obtained by dividing the force measured by the probe cross-sectional area. The experimental strain was obtained from the probe displacement.

The gel-cell interaction was assessed using L929 mouse fibroblast cells as reported in our previous work. ${ }^{35}$ The L929 fibroblast cells were sub-cultured in DMEM-GX media using a standard cell culture protocol. The hydrogels were directly fabricated into a 96 -well plate and dialyzed with Milli-Q water. The hydrogels were then sterilized with $80 \%$ ethanol for 4 hours and rehydrated in cell culture medium for 2 days. The excess medium was then removed from the culture plate, and the cells (at a density of $1 \times 10^{4}$ cells/well) were gently loaded on the hydrogel surface. The culture plate was then gently topped up with fresh medium and placed in an incubator $\left(5 \% \mathrm{CO}_{2}\right)$ at $37^{\circ} \mathrm{C}$. The cell viability was quantitatively assessed using trypan blue dye. Dead cells uptake the dye due to their damaged cell membranes, whereas live cells exclude the dye due to their intact cell membranes. ${ }^{35}$ About $10 \mu \mathrm{L}$ of trypan blue dye was gently mixed with $10 \mu \mathrm{L}$ of trypsinized cells and evaluated using an Invitrogen Countess Automated Cell Counter. The cell proliferation or metabolic activity at day 1 on fabricated hydrogels was measured using the MTS [3-(4,5-dimethyl-2-yl)-5-(3-carboxymethoxyphenyl)-2-(4- 
sulfophenyl)-2H-tetrazolium] assay - in the living cell environment, the tetrazolium compound MTS is converted to the formazan product. ${ }^{35}$ About $10 \mu \mathrm{L}$ of MTS reagent was added to the wells containing hydrogels and incubated for 4 hours. The supernatant (containing formazan) was then transferred to a fresh plate and the absorption value was measured at $490 \mathrm{~nm}$ using a SpectraMax Microplate Reader. The positive control was tissue culture plate (TCP). Fixation of cells for SEM analysis was carried out as follows: primary fixation of cells on hydrogels after 2, 4, 6 hours and 1, 4, 7 days was carried out by treating the samples with glutaraldehyde/paraformaldehyde (30 min) and sodium cacodylate buffer (5 min); secondary fixation was carried out by treating the samples with $1 \%$ osmium tetroxide (30 min) in the dark, followed by sequential washing (10 min each step) of fixed samples in water/ethanol mixture with increase in ethanol content from 0 to 100 vol\% and air-drying.

\section{RESULTS AND DISCUSSION}

Water uptake and microstructure: The equilibrium swelling and crosslinked network structure are important parameters for hydrogel performance when applied in drug delivery and tissue engineering. The swelling ratio, crosslink density, micropores, and hierarchical structure of hydrogels influence their viscoelastic properties and the gel-cell interactions. ${ }^{36}$ The sample code, equilibrium water swelling ratio, and crosslink density are given in Table 1 . The Rec1 hydrogel exhibits a swelling ratio and a crosslink density of $3.30 \pm 0.12$ and $0.292 \pm 0.001$ $\times 10^{-3} \mathrm{~mol} / \mathrm{cm}^{3}$, respectively, which are in agreement with values reported previously. ${ }^{13}$ The water swelling ratio increased with increasing GO content, whereas the crosslink density systematically decreased. The Rec1/GO3 hybrid hydrogel exhibits a swelling ratio of $4.38 \pm$ 0.15 , which is a $33 \%$ increase from pristine Rec1 hydrogel and suggests that the hybrid hydrogels become more hydrophilic with GO incorporation. Such an increase in hydrophilicity can influence the micromechanical and cell interaction properties. The observed increase in the swelling ratio of Rec1/GO hybrid hydrogels can be related to the hydrophilic nature and large 
specific surface area of GO, which may in turn hinder the di-tyrosine crosslink formation between Rec1 molecules, by either acting as a physical barrier or through inter-molecular interactions, thereby decreasing their crosslink density. ${ }^{27}$ Figure $2 \mathrm{~A}$ shows optical images, and Figure 2B shows SEM micrographs after equilibrium water swelling and freeze-drying. The SEM micrograph of photocrosslinked Recl hydrogel shows a microporous interconnected network structure, which is similar to that of $R Z_{10}-R G D$ hydrogel (where $R Z_{10}$ is a $R L P$ encoded from the mosquito Anopheles gambiae gene, and RGD is a cell binding domain) crosslinked via a Michael-type addition reaction. ${ }^{37}$ Such porous structures facilitate diffusion and transport of nutrients and gases for tissue engineering applications. ${ }^{38}$ However, with increase in GO content, the micropore size is observed to change systematically (Table 1). The average pore size of Rec1 hydrogel is $4.36 \pm 0.53 \mu \mathrm{m}$, which increases to $6.12 \pm 1.16 \mu \mathrm{m}$ with incorporation of $0.2 \mathrm{wt} \%$ GO. This increase in average pore size is consistent with the trend observed for equilibrium water swelling (Table 1).

(A)

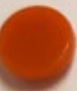

(a)

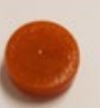

(b)

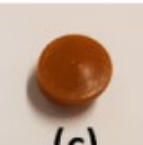

(c)

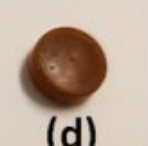

(d)

(B)
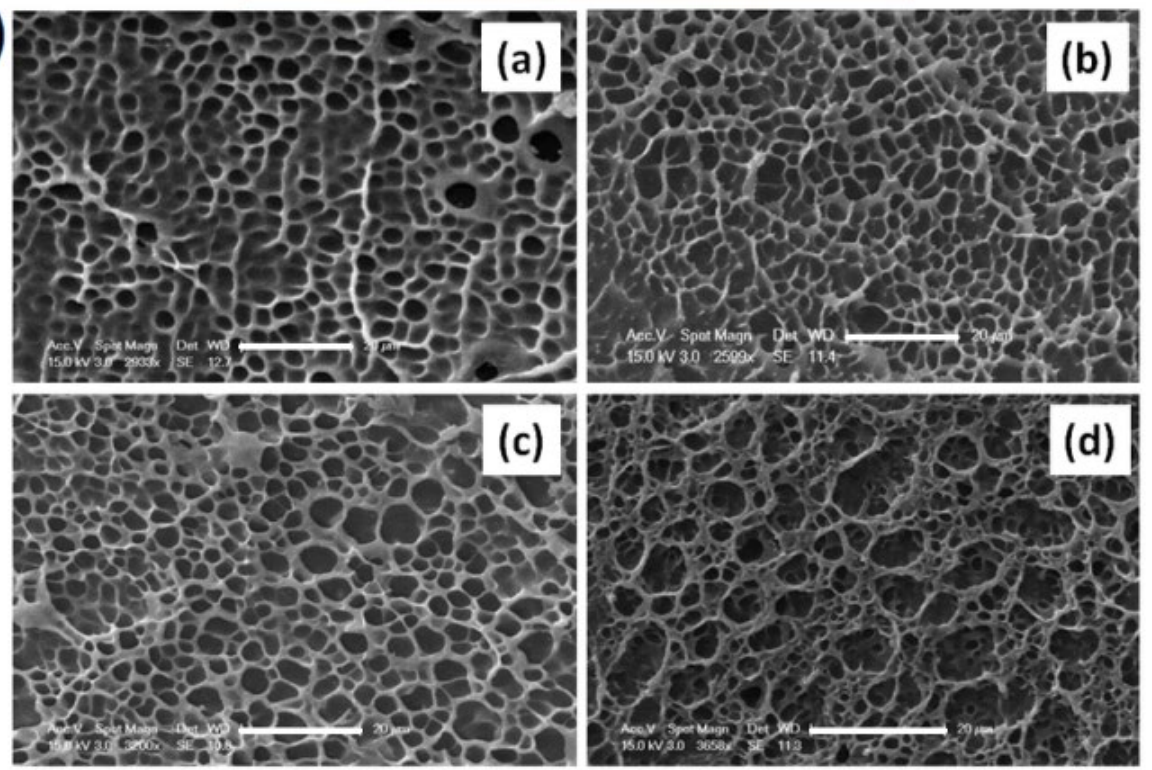
Figure 2. (A) Optical images and (B) SEM micrographs (freeze dried; $20 \mu \mathrm{m}$ scale bar) of fabricated hydrogels: (a) Rec1 hydrogel, (b) Rec1/GO1 hybrid hydrogel, (c) Rec1/GO2 hybrid hydrogel and (d) Rec1/GO3 hybrid hydrogel.

Table 1. Water uptake, microstructure, and micromechanical properties of fabricated hydrogels.

\begin{tabular}{|c|c|c|c|c|c|}
\hline \multirow[t]{2}{*}{ Sample } & \multirow{2}{*}{$\begin{array}{c}\text { GO } \\
\text { content } \\
(\mathbf{w t} \%)\end{array}$} & \multicolumn{2}{|c|}{ Water uptake } & SEM & \multirow{2}{*}{$\begin{array}{c}\text { Micro- } \\
\text { indentation }\end{array}$} \\
\hline & & $\begin{array}{c}\text { Swelling } \\
\text { ratio }\end{array}$ & $\begin{array}{c}\text { Crosslink } \\
\text { density }\left(\times 10^{-3}\right. \\
\left.\mathbf{m o l} / \mathbf{c m}^{3}\right)\end{array}$ & $\begin{array}{l}\text { Pore size } \\
\qquad(\mu \mathrm{m})\end{array}$ & \\
\hline Rec1 gel & - & $3.30 \pm 0.12$ & $0.292 \pm 0.001$ & $4.36 \pm 0.53$ & $1.30 \pm 0.11$ \\
\hline Rec1/GO1 gel & 0.02 & $3.55 \pm 0.14$ & $0.291 \pm 0.001$ & $4.41 \pm 0.91$ & $1.17 \pm 0.16$ \\
\hline Rec1/GO2 gel & 0.10 & $3.90 \pm 0.11$ & $0.289 \pm 0.001$ & $5.09 \pm 0.98$ & $1.11 \pm 0.22$ \\
\hline Rec1/GO3 gel & 0.20 & $4.38 \pm 0.15$ & $0.287 \pm 0.001$ & $6.12 \pm 1.16$ & $1.06 \pm 0.30$ \\
\hline
\end{tabular}

Hierarchical network structure: SANS and USANS are excellent techniques for investigating the hierarchical structure of hydrogels across length scales from $1 \mathrm{~nm}$ to 50 $\mu \mathrm{m} .{ }^{32,39}$ Moreover, the contrast-variation/matching capability of neutrons, through their unique interaction with hydrogen and deuterium (isotope), provides effective means to investigate the structure and organization of individual components in hybrid/composite hydrogels. ${ }^{40}$ Figure 3A shows the SANS and USANS profiles of $\mathrm{D}_{2} \mathrm{O}$ swollen Rec1 hydrogel and Rec1/GO3 hybrid hydrogel. The neutron scattering length density (SLD) of Rec1 in $\mathrm{D}_{2} \mathrm{O}\left(\sim 2.8 \times 10^{-6} \AA^{-2}\right)$ provides sufficient scattering contrast against $100 \% \mathrm{D}_{2} \mathrm{O}\left(6.36 \times 10^{-6} \AA^{-2}\right)$ as well as against GO in $\mathrm{D}_{2} \mathrm{O}\left(\sim 6.1 \times 10^{-6} \AA^{-2}\right) \cdot{ }^{10,41}$ Therefore, the scattering contribution from $\mathrm{GO}$ in $\mathrm{Rec} 1 / \mathrm{GO} 3$ hybrid hydrogel is contrast matched in $\mathrm{D}_{2} \mathrm{O}$, and the measured scattering data are only from 
Rec1. The scattering profile of Rec1 hydrogel shows five distinct regions: a high-q Porod region $\left(0.05<\mathrm{q}<0.3 \AA^{-1}\right)$, a high-q Guinier region $\left(0.015<\mathrm{q}<0.05 \AA^{-1}\right)$, a mid-q Porod-like region $\left(0.006<\mathrm{q}<0.015 \AA^{-1}\right)$, a mid-q Guinier-like region $\left(0.001<\mathrm{q}<0.006 \AA^{-1}\right)$, and a lowq Porod-like region $\left(0.00004<\mathrm{q}<0.001 \AA^{-1}\right)$. The Rec1/GO3 hybrid hydrogel showed only four distinct regions, with no clear high-q Guinier region. This difference can be clearly noticed in the Kratky plot (Figure 3B), which accentuates features. ${ }^{42}$ At low-q, power law behaviour of $\mathrm{q}^{-2.9}$ is observed in the scattering profile of both hydrogels (Figure 3A) suggesting the presence of mass fractal or network structures extending beyond the USANS measurement range. The Kratky plot (Figure 3B) shows peaks at low-q $\left(q=0.000143 \AA^{-1}\right.$ and $q=0.000109$ $\AA^{-1}$ ) which correspond to structural inhomogeneities in Rec1 hydrogel and Rec1/GO hybrid hydrogel, with calculated (using the relation $d=2 \pi / q){ }^{33}$ feature sizes (d) of $4.4 \mu \mathrm{m}$ and $5.8 \mu \mathrm{m}$, respectively. These features are attributed to the micropores in the hydrogels in accordance with the pore size range estimated from SEM micrographs (Table 1). 

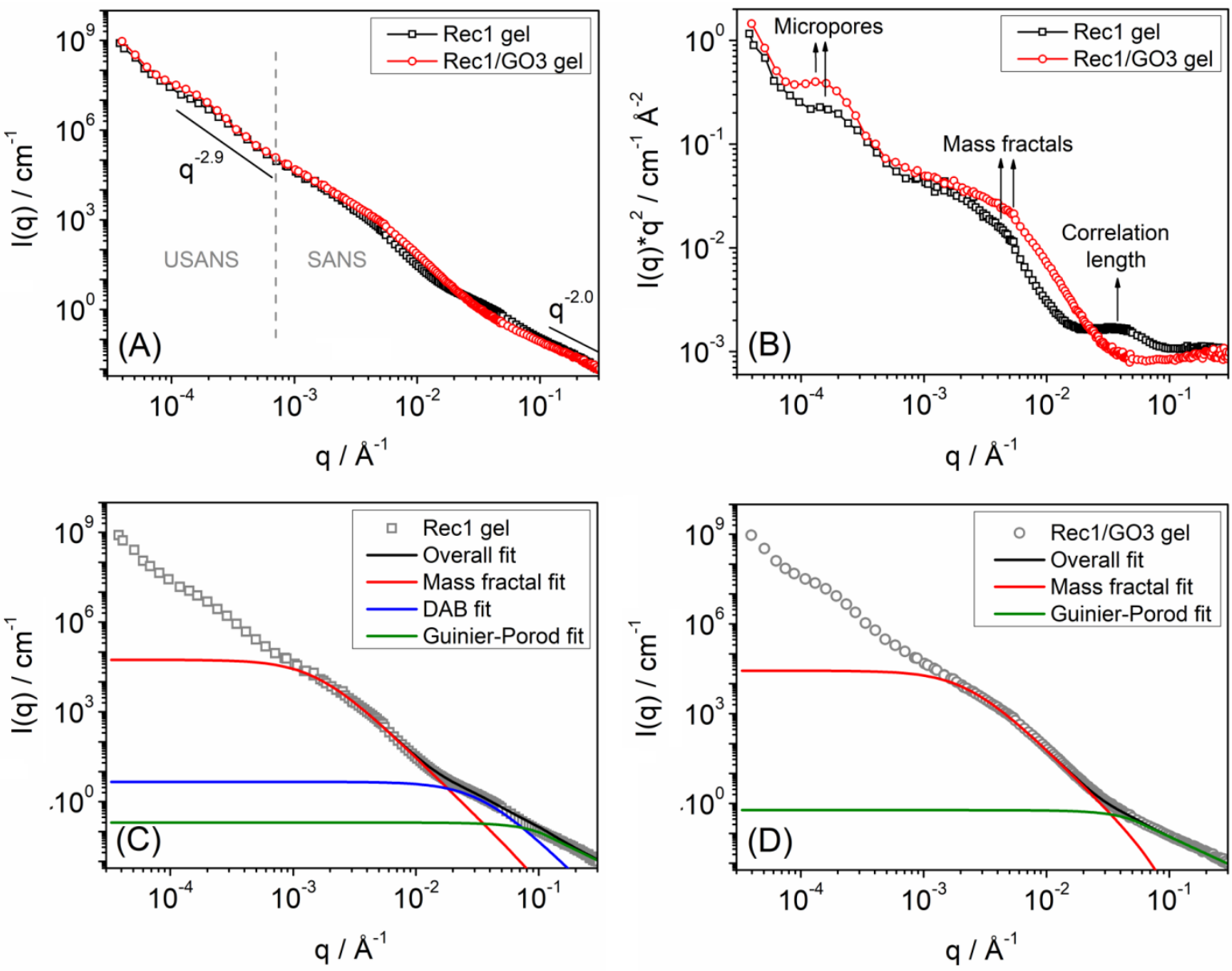

Figure 3. (A) SANS and USANS profile, and (B) Kratky plot of hydrogels equilibrium swollen in $\mathrm{D}_{2} \mathrm{O}$. Shape-independent functions fit to SANS data of (C) Rec1 hydrogel and (D) Rec1/GO3 hybrid hydrogel.

In general, the Porod region slope (Porod slope) in the scattering profile reveals the scattering object's fractal dimension; whereas, the Guinier region plateau reveals their fractal sizes. $^{32}$ The scattering profiles of Rec1 hydrogel and Rec1/GO hybrid hydrogel (Figure 3A) display high-q $(0.1<\mathrm{q}<0.3)$ power law behaviour of $\mathrm{q}^{-2.0}$ and $\mathrm{q}^{-1.9}$, respectively, which is characteristic of Gaussian coil polymer chains in a theta solvent. ${ }^{43}$ This characteristic is also evident from the Kratky plot, which shows a plateau (characteristic of unordered structure) in the high-q $(0.1<\mathrm{q}<0.3)$ region (Figure $3 \mathrm{~B})$. The Porod slopes of these hydrogels are similar to that reported for Rec1 solution data, suggesting that the unordered structure of Rec1 is 
conserved in these photocrosslinked hydrogels. ${ }^{10}$ The nanostructural parameters of Rec1 hydrogel are obtained by fitting a combined form factor shape-independent function (equation 4) to the processed scattering data (Figure 3C).

$$
I(q)=C(q)+B(q)+A(q)
$$

where $\mathrm{A}(\mathrm{q})$ is the Guinier-Porod model, $\mathrm{B}(\mathrm{q})$ is the Debye-Anderson-Brumberger (DAB) model, and C(q) is the mass fractal model. For Rec1/GO3 hybrid hydrogel, only A(q) and C(q) are necessary to fit the data (Figure 3D), as no clear high-q Guinier region is present. The structural parameters obtained from shape-independent model fits are tabulated in Table 2 . The Guinier-Porod model predicts the size and shape (asymmetric to symmetric) of a generalized Guinier/power law object; ${ }^{44}$ whereas, the DAB model predicts the correlation length of a twophase system (randomly distributed), for example an inter-domain distance between polypeptide rich regions or domains. ${ }^{45}$ The mass fractal model estimates the fractal dimension and size of fractal-like clusters. ${ }^{46}$

Table 2. Structural parameters of fabricated hydrogels obtained from SANS data fit.

\begin{tabular}{lcccc}
\hline Sample & $\begin{array}{c}\text { Guinier-Porod } \\
\text { model fit (high-q) }\end{array}$ & $\begin{array}{c}\text { DAB model fit } \\
(\mathbf{m i d}-q)\end{array}$ & \multicolumn{2}{c}{ Mass fractal model fit (low-q) } \\
\cline { 2 - 5 } & Rg $(\mathbf{n m})$ & $\begin{array}{c}\text { Correlation } \\
\text { length }(\mathbf{n m})\end{array}$ & $\begin{array}{c}\text { Fractal size } \\
(\mathbf{n m})\end{array}$ & $\begin{array}{c}\text { Fractal } \\
\text { dimension }\end{array}$ \\
\hline Rec1 gel & $1.52 \pm 0.04$ & $3.05 \pm 0.04$ & $65.08 \pm 1.25$ & $3.00 \pm 0.05$ \\
Rec1/GO3 & $3.01 \pm 0.05$ & - & $45.09 \pm 1.53$ & $3.00 \pm 0.04$ \\
gel & & & & \\
\hline
\end{tabular}

The radius of gyration $(\mathrm{Rg})$ of Rec1 domains in photocrosslinked Rec1 hydrogel of 1.5 $\mathrm{nm}$ is smaller than the value of $5 \mathrm{~nm}$ reported in aqueous solutions, which is attributed to intramolecular crosslinking. ${ }^{10}$ Rec1 forms only hydrophilic domains upon photocrosslinking, which 
is supported by the estimated high-q Porod slope of $-2 .{ }^{33}$ These hydrophilic Rec1 domains in the pristine photocrosslinked Rec1 hydrogel are separated by a correlation length of $3 \mathrm{~nm}$. By comparison, the $\mathrm{Rg}$ of the Rec1 domains in the Rec1/GO3 hybrid hydrogel are approximately twice as large at $3 \mathrm{~nm}$ and are randomly distributed (no correlation length). The networks of mass fractal structures in the pristine and hybrid gels are similar with a fractal dimension of 3. However, the size of the mass fractals in the Rec1/GO3 hybrid hydrogel is smaller $(\mathrm{Rg} \sim 45.1$ $\mathrm{nm})$ than that in the $\operatorname{Rec} 1$ hydrogel $(\mathrm{Rg} \sim 65.1 \mathrm{~nm})$. It is postulated that the fractal structures are smaller in Rec1/GO3 and randomly distributed due to the dispersed GO platelets in the hydrogel matrix. It is likely that the higher water uptake capacity of the Rec1/GO3 hybrid hydrogel compared to the Rec1 hydrogel is due to its larger micropore size, larger hydrophilic Rec1 domain size, and the highly hydrophilic nature of GO. The question then arises as to whether the influence of GO on the matrix is due to physical or chemical interactions or a combination of both.

Molecular interaction and chain dynamics: In order to further investigate the observed difference in the structural features between Rec1 hydrogel and Rec1/GO3 hybrid hydrogel, FTIR and DSC experiments were performed. Tyrosine amino acid residues have been reported to interact with GO through $\mathrm{H}$-bonding, charge transfer, and $\pi-\pi$ stacking (Figure 1). ${ }^{47}$ Compared to Rec1 hydrogel, no additional chemical bonds were observed in the FTIR spectra of Rec1/GO3 hybrid hydrogel (Figure 4A). Both hydrogels exhibit absorption peaks at 3267, $3064,2925,1633,1516,1438,1338$ and $1026 \mathrm{~cm}^{-1}$ corresponding to N-H stretching, N-H stretching, $\mathrm{v}\left(\mathrm{CH}_{2}\right)$, Amide I $(\mathrm{C}=\mathrm{O})$, Amide II $(\mathrm{C}-\mathrm{N}$ stretching, $\mathrm{N}-\mathrm{H}$ bending $), \mathrm{v}\left(\mathrm{CH}_{2}\right), \mathrm{v}(\mathrm{CH})$ and C-N stretching, respectively. ${ }^{14}$ Furthermore, the incorporation of GO into Rec1 hydrogel matrix does not change the molecular chain dynamics of Rec1, where no change in glass transition temperature $\left(\sim 195^{\circ} \mathrm{C}\right)$ or breadth was observed (Figure 4B). 

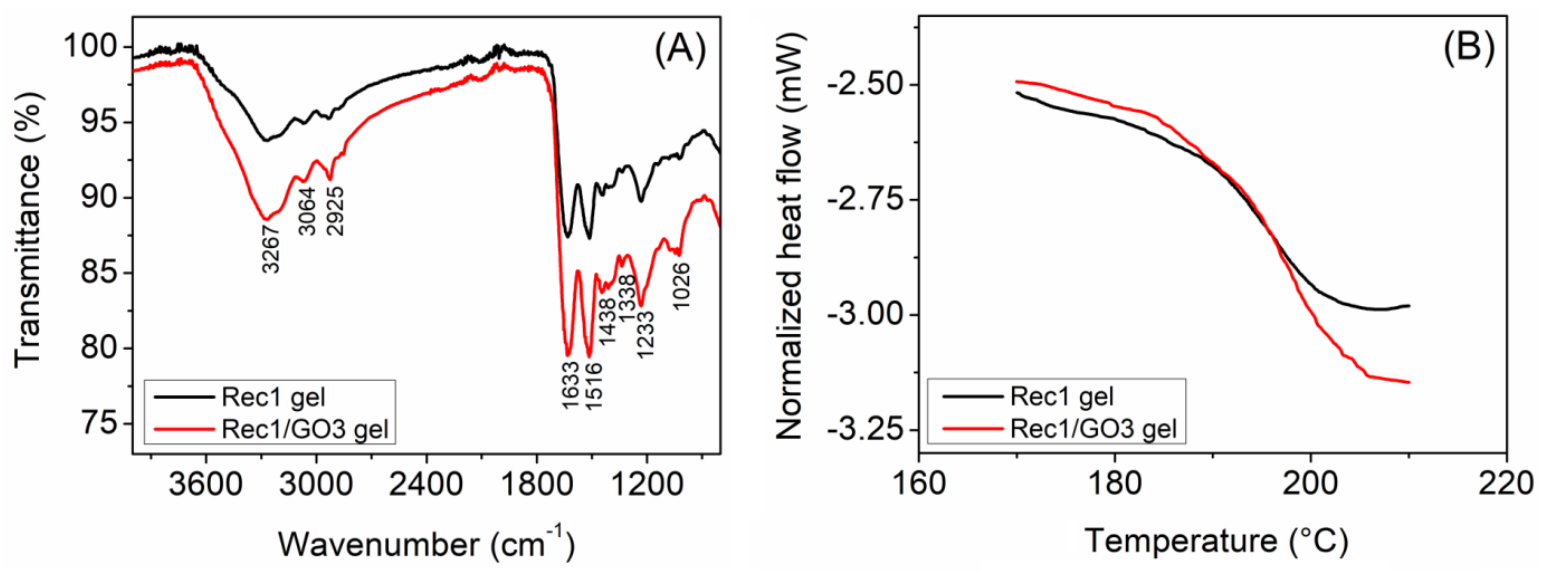

Figure 4. (A) FTIR spectra and (B) DSC thermograms (showing glass transition temperature) of Rec1 hydrogel and Rec1/GO3 hybrid hydrogel.

Micromechanical properties: The stiffness, density, and viscoelastic characteristics of hydrogels affect gel-cell interactions and cell phenotype. ${ }^{48}$ The compressive micromechanical properties of Rec1/GO hybrid hydrogels were measured using small strain micro-indentation testing. Figure 5A to 5D shows the cyclic compression loading-unloading curves of fabricated hydrogels subjected to $20 \%, 40 \%, 60 \%$ and $80 \%$ strain in the equilibrium water swollen condition. The compressive elastic modulus of the fabricated hydrogels was derived from the stress-strain loading curve (slope between $0 \%$ and $5 \%$ strain). The elastic moduli with population standard deviations are given in Table 1. The Rec1 hydrogel exhibits an elastic modulus of $1.30 \pm 0.11$, which systematically decreases marginally (with increase in GO content) to $1.06 \pm 0.30$ for Rec1/GO3 hybrid hydrogel. These values are observed to lie between the values of $0.45 \mathrm{kPa}$ and $1.83 \mathrm{kPa}$ reported for $5 \mathrm{wt} \%$ and $10 \mathrm{wt} \% \mathrm{RLP}_{12}-\mathrm{LCD}_{5}$ hydrogels (crosslinked using tri(hydroxymethyl) phosphine-based condensation reaction), respectively; where $\mathrm{RLP}_{12}$ is encoded from the fruitfly D. melanogaster gene, and LCD is lysine crosslinking domain. ${ }^{23}$ Interestingly, these elastic moduli are significantly lower than the $11.65 \mathrm{kPa}$ modulus reported for $20 \mathrm{wt} \% \mathrm{RLP}_{12}-\mathrm{LCD}_{5}$ hydrogel. ${ }^{23}$ The elastic moduli of our hydrogels are similar to those of $\mathrm{RZ}_{10}-\mathrm{RGD}$ hydrogel (crosslinked via a Michael-type addition 
reaction $)^{37}$ and are in the range of values reported for hydrogels used to regulate tissues of neurons $(0.1-1 \mathrm{kPa}),{ }^{49}$ adipocytes $(1-2 \mathrm{kPa}),{ }^{50}$ and chondrocytes $(1-3.5 \mathrm{kPa}) .{ }^{51}$ It is postulated that the marginal difference in elastic moduli of Rec1 hydrogel and Rec1/GO hybrid hydrogels is related to their water content, given that the swelling ratio of these hydrogels increases with increase in GO content. These results support the potential application of these Rec1 and Rec1/GO hydrogels in soft tissue engineering.
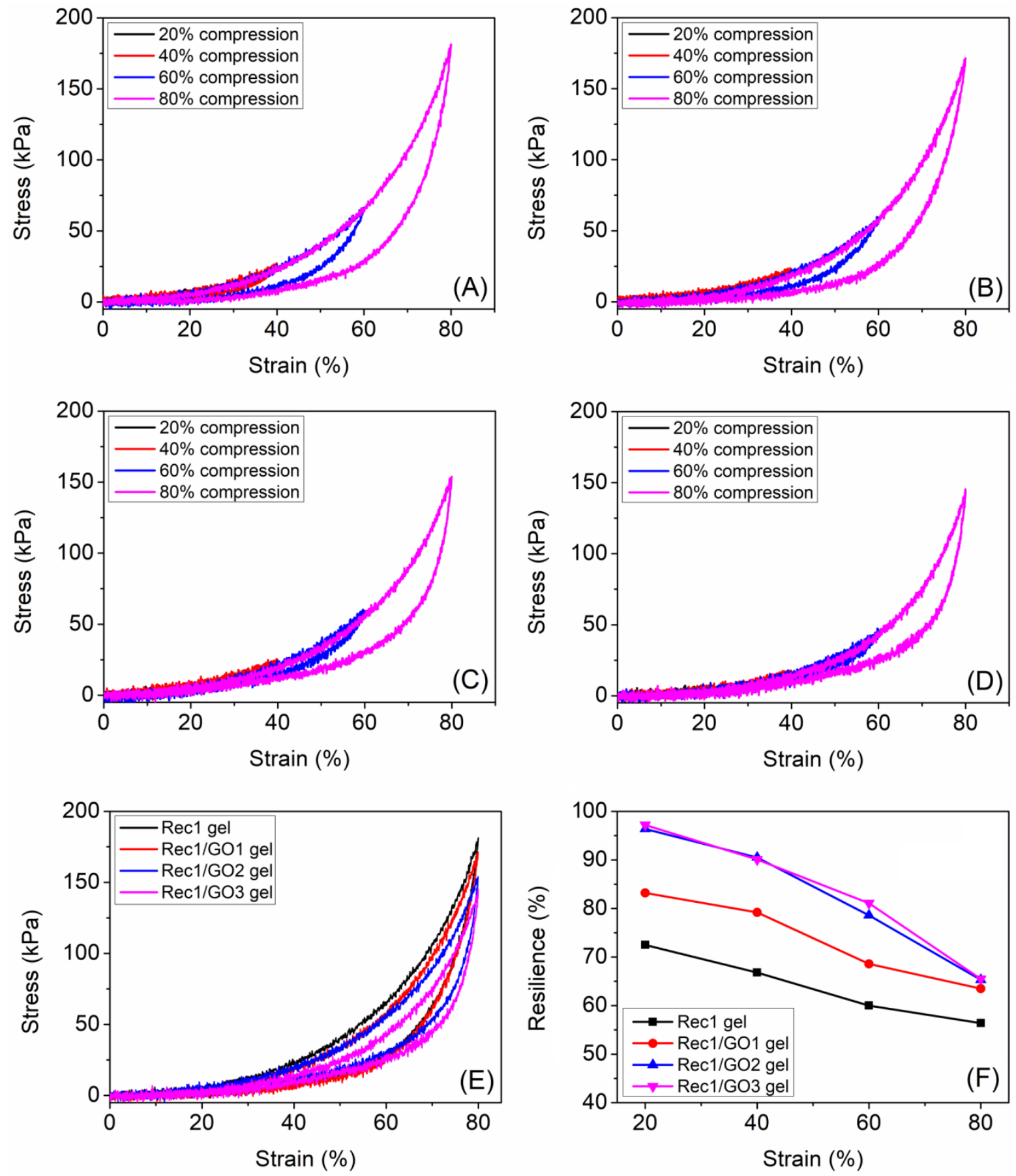
Figure 5. Cyclic compression loading-unloading curves of (A) Rec1 hydrogel, (B) Rec1/GO1 hybrid hydrogel, (C) Rec1/GO2 hybrid hydrogel, and (D) Rec1/GO3 hybrid hydrogel. (E) Comparison of cyclic compression (80\%) loading-unloading curves, and (F) micromechanical resilience of fabricated hydrogels.

Figure 5E compares the cyclic compression loading-unloading curves of fabricated hydrogels subjected to $80 \%$ strain, where the decrease in hysteresis area and compression strength can be clearly observed for hydrogels with increasing GO content. This hysteresis result indicates an increase in resilience (the ability of a material to spring back to its shape) of the hydrogels with an increase in GO content. The micromechanical resilience values of these hydrogels are calculated from their compression loading-unloading curves (ratio of the area under the unloading curve to the loading curve) at $20 \%, 40 \%, 60 \%$ and $80 \%$ strain as presented in Figure 5F. The Rec1 hydrogel exhibits a compressive resilience of $72.5 \%$ for $20 \%$ strain, which systematically decreases to $56.4 \%$ for $80 \%$ strain (Figure 6). The resilience values reported here are lower than values generally reported for resilins measured using scanning probe microscopy (SPM). ${ }^{5}$ The probe penetration is only a few hundred nanometers into the surface of the material for SPM, whereas micrometer scale penetration occurs for the small strain micro-indentation used here. The micro-scale deformation relies on cooperative segmental motion of the polypeptide chains resulting in loss of resilience due to internal friction. ${ }^{37}$ Therefore, the difference in measured resilience can be attributed to difference in experimental parameters such as depth of penetration, probe size, and maximum strain values used for the various mechanical property measurement techniques. ${ }^{52}$ The measured resilience of Rec1 hydrogel (73\%) is slightly higher than that of RZ 10 -RGD hydrogel (70\%) but lower than the value of $87 \%$ reported for $\mathrm{RLP}_{12}-\mathrm{LCD}_{5}$ hydrogel. ${ }^{23,37}$ Unlike $\mathrm{RLP}_{64}$ hydrogel (crosslinked using carbodiimide chemistry), which showed a decrease in resilience from 98\% to $82 \%$ with incorporation of $\mathrm{GO},{ }^{22} \mathrm{Rec} 1$ hydrogel shows an increase in resilience at all strains 
with incorporation of GO (Figure 6). The resilience of Rec1/GO hybrid hydrogels increases with incorporation of GO and appears to plateau at $\sim 0.1 \mathrm{wt} \% \mathrm{GO}$ content. One possible reason for this could be that the percolation threshold is achieved at that ratio due to high surface area of GO (edge to edge connectivity in the composite). ${ }^{53}$ Also, it is presumed that further improvements or modifications in micromechanical properties of Rec1/GO hybrid hydrogels can be achieved by chemically modifying GO and covalently connecting to Rec 1 .

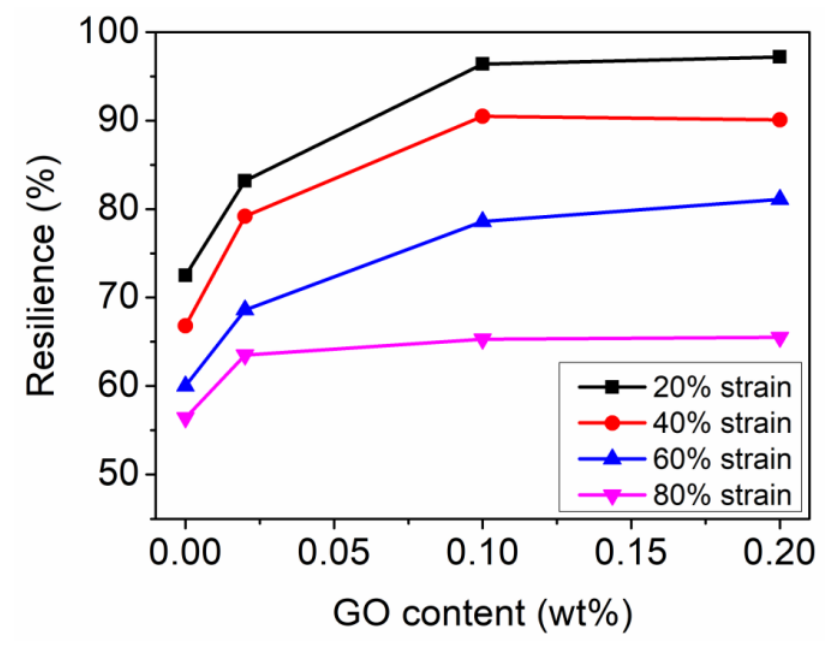

Figure 6. Resilience of fabricated hydrogels at different strain as a function of GO content.

In vitro cell viability, proliferation and interaction: The L929 mouse fibroblast is a highly adherent cell line, most commonly used to study cell attachment and viability of hydrogels for tissue engineering and regeneration applications. The fibroblast cells undergo two different states of cell attachment and spreading based on substrate stiffness: on a stiff substrate (elastic modulus $>5 \mathrm{kPa}$ ) the cells are completely spread with stress fibers, whereas on soft substrates (moduli $\sim 1-5 \mathrm{kPa}$ ) the cells are not fully spread and possess no stress fibers. ${ }^{54}$ The cell attachment and proliferation properties of Rec1 hydrogel and Rec1/GO3 hydrogel were investigated by culturing L929 mouse fibroblast cells on the hydrogel surface. The attachment of fibroblast cells on the hydrogel surfaces was examined using SEM. Figure 7A shows the SEM micrographs of hydrogel surfaces cultured with fibroblast cells, examined after 2, 4, 6 
hours, and 1, 4, 7 days, respectively. The Rec1 hydrogel showed very minimal cell attachment with only a few cells attached on the surface at 2 hours. The rounded cell phenotype remained the same, whereas the number of cells on the surface was observed to decrease with time. At day 7, almost no cell attachment was observed on the gel surface. The Rec1/GO3 hybrid hydrogel also showed very limited (with rounded cell phenotype) or no cell attachment for all time periods examined, suggesting no change in cell attachment properties of Rec1 hydrogel with incorporation of GO $(0.2 \mathrm{wt} \%)$. Figure $7 \mathrm{~B}$ shows the absorbance signal measured from the MTS assay at day 1, where the cell proliferation is proportional to the absorption coefficient. The absorbance signal of the fabricated hydrogels was observed to be significantly lower (around 75\% reduction) than the control (TCP), which indicates minimal cell proliferation on Rec1-based hydrogel surfaces. The slightly higher (10\% increase) absorbance value of Rec1/GO3 hybrid hydrogel compared to pristine Rec1 hydrogel indicates marginal improvement in cell proliferation on hydrogels with $0.2 \mathrm{wt} \% \mathrm{GO}$ incorporation. On the other hand, the cell viability of Rec1 hydrogel evaluated using the trypan blue assay was observed to decrease (Figure 7C) with incorporation of GO. Increase in cell proliferation and impaired cell viability has been previously reported for nano- and micro-sized GO for embryonic fibroblast cells where GO negatively regulates cell cycle. ${ }^{55}$ At $0.2 \mathrm{wt} \% \mathrm{GO}$, these highly hydrophilic gels behave like repellent polyethylene glycol (PEG) surfaces due to the high degree of hydration. Cell-inert polymer surfaces are generally dominated by non-adhesion interaction. The very limited or non-cell-adherent property (cell inertness) of the Rec1 hydrogel matrix is expected to lead to reduced interactions in physiological environments, including the mononuclear phagocyte system (MPS) or other complementary systems, thereby improving the blood circulation half-life and the immune system clearance, which can make these hydrogels suitable as stealth protein-conjugates for drug delivery. ${ }^{56}$ On cell-inert gels, the adsorption of plasma membrane proteins is hindered by strong surface hydration or 
electrostatic repulsion. At $\mathrm{pH} 7.4$, the partial deprotonation of the surface carboxyl groups on GO renders it negatively charged, while resilin also has negative charge (isoelectric point, $\mathrm{pI}=$ 4.9). ${ }^{7,25}$ Our hypothesis is that electrostatic repulsion dominates the cell interaction property. Further studies will be required to validate this hypothesis including measurement of immune cell response. Such studies are the subject of future work.

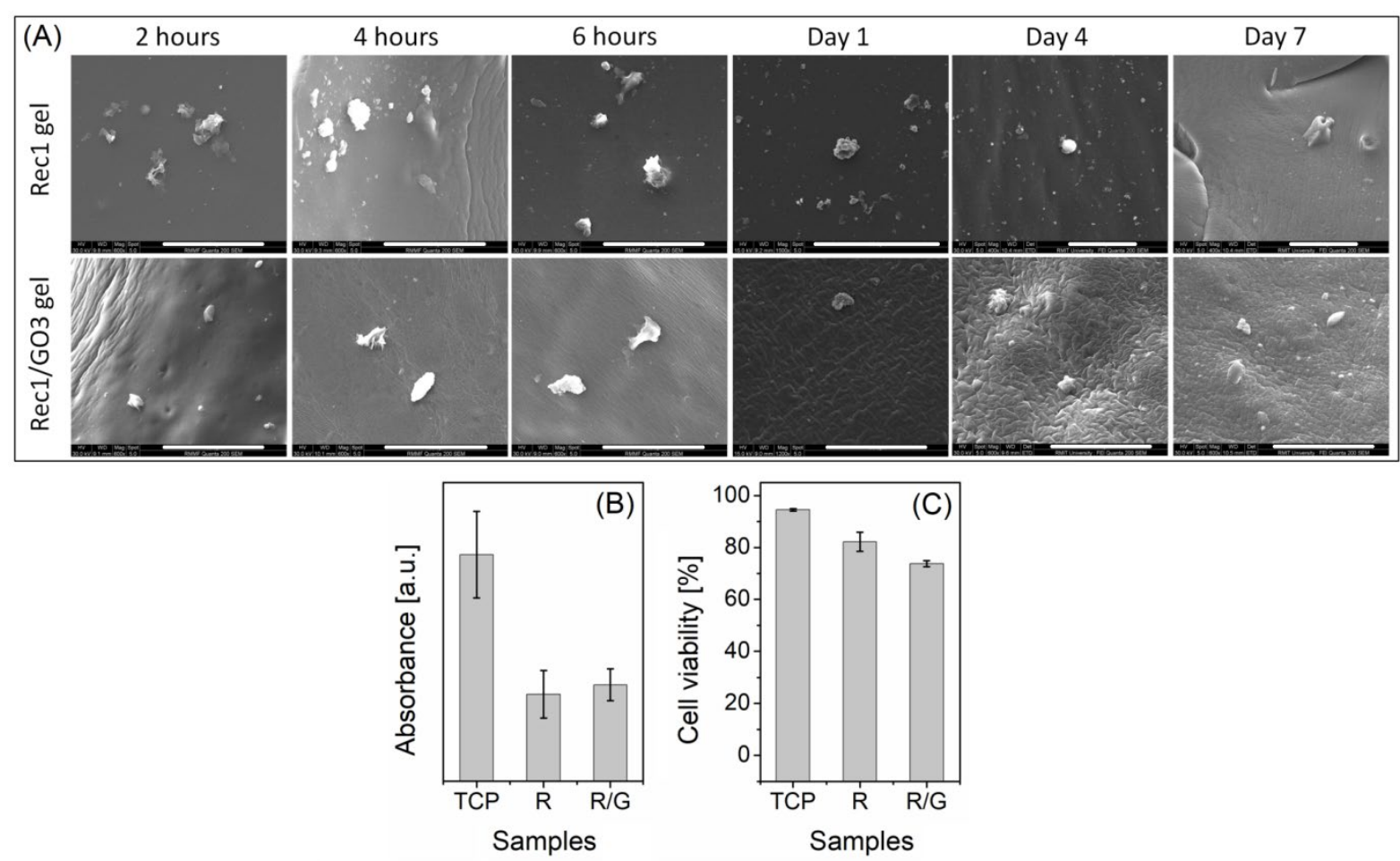

Figure 7. (A) SEM images (100 $\mu \mathrm{m}$ scale bar) of the L929 mouse fibroblast cells cultured and fixed on the surface of Rec1 hydrogels and Rec1/GO3 hybrid hydrogels. (B) Absorbance signal measured from MTS cell proliferation assay, and (C) percentage of cell viability determined using the trypan blue exclusion assay at day 1 . The sample codes used are (TCP) - tissue culture plate, (R) - Rec1 hydrogel, and (R/G) - Rec1/GO3 hydrogel.

\section{CONCLUSIONS}


Rec1/GO hybrid hydrogels have been successfully fabricated using a photocrosslinking method. Contrast matching SANS and USANS reveal the structure of the Rec1 hydrogel matrix as made up of crosslinked hydrophilic Rec1 domains, separated by a correlation length, and clustered as mass fractals. Increasing the GO content to $0.2 \mathrm{wt} \%$ in di-tyrosine crosslinked Rec1 hydrogel matrices increases the equilibrium swelling ratio, micropore size, and crosslinked domain size whilst decreasing the crosslink density, order of crosslinked domain distribution, and their mass fractal cluster size. In addition, incorporation of GO $(0.2 \mathrm{wt} \%)$ in the Rec1 hydrogel matrix shows no effects on cell attachment properties, although initially a marginal increase in cell proliferation is observed with a subsequent decrease in cell viability. The tested levels of GO in Rec1/GO hybrid hydrogels show only a slight/marginal decrease in compressive elastic modulus of Rec1 hydrogel with increase in GO content. The micromechanical resilience of Rec1/GO hybrid hydrogels increases up to a GO content of 0.1 $\mathrm{wt} \%$ and then remains stable, whereas the resilience decreases with increase in strain for all GO loadings ( 0 to $0.2 \mathrm{wt} \%$ ). In conclusion, incorporation of GO $(0.2 \mathrm{wt} \%)$ in Rec1/GO hybrid hydrogels shows improved hydrophilicity, resilience, amorphous domain size and cell proliferation characteristics compared to pristine Rec1 hydrogel, which can potentially expand their application in biomedical engineering with tuneable surface properties for switching between cell-active and cell-inert surfaces.

\section{Author Contributions}

The manuscript was written through contributions of all authors. All authors have given approval to the final version of the manuscript.

\section{Notes}

The authors declare no competing financial interest. 


\section{ACKNOWLEDGEMENTS}

This research was supported by the Australian Research Council's Discovery Projects funding scheme (project DP160101267). The authors acknowledge the facilities, and the scientific and technical assistance of the RMIT Microscopy \& Microanalysis Research Facility (especially Dr. Chaitali Dekiwadia for Bio-EM data analysis), RMIT Micro Nano Research Facility, and BioFab3D of St. Vincent's Hospital (Melbourne). SANS and USANS experiments at ACNS was supported by ANSTO's beamtime award (P6656). This work benefited from the use of free SasView application (https://www.sasview.org/).

\section{REFERENCES}

(1) Jonker, A. M.; Löwik, D. W. P. M.; van Hest, J. C. M., Peptide- and protein-based hydrogels. Chem. Mater. 2012, 24 (5), 759-773.

(2) Bailey, A. J.; Macmillan, J.; Shrewry, P. R.; Tatham, A. S.; Gosline, J.; Lillie, M.; Carrington, E.; Guerette, P.; Ortlepp, C.; Savage, K., Elastic proteins: biological roles and mechanical properties. Philos. Trans. R. Soc., B 2002, 357 (1418), 121-132.

(3) Balu, R.; Whittaker, J.; Dutta, N. K.; Elvin, C. M.; Choudhury, N. R., Multiresponsive biomaterials and nanobioconjugates from resilin-like protein polymers. J. Mater. Chem. B 2014, 2 (36), 5936-5947.

(4) Elvin, C. M.; Carr, A. G.; Huson, M. G.; Maxwell, J. M.; Pearson, R. D.; Vuocolo, T.; Liyou, N. E.; Wong, D. C. C.; Merritt, D. J.; Dixon, N. E., Synthesis and properties of crosslinked recombinant pro-resilin. Nature 2005, 437 (7061), 999-1002.

(5) Su, R. S. C.; Kim, Y.; Liu, J. C., Resilin: Protein-based elastomeric biomaterials. Acta Biomater. 2014, 10 (4), 1601-1611.

(6) Li, L.; Kiick, K. L., Resilin-based materials for biomedical applications. ACS Macro Lett. 2013, 2 (8), 635-640.

(7) Dutta, N. K.; Truong, M. Y.; Mayavan, S.; Roy Choudhury, N.; Elvin, C. M.; Kim, M.; Knott, R.; Nairn, K. M.; Hill, A. J., A Genetically engineered protein responsive to multiple stimuli. Angew. Chem. Int. Ed. 2011, 50 (19), 4428-4431.

(8) Balu, R.; Dutta, N. K.; Choudhury, N. R.; Elvin, C. M.; Lyons, R. E.; Knott, R.; Hill, A. J., An16-resilin: An advanced multi-stimuli-responsive resilin-mimetic protein polymer. Acta Biomater. 2014, 10 (11), 4768-4777. 
(9) Balu, R.; Knott, R.; Cowieson, N. P.; Elvin, C. M.; Hill, A. J.; Choudhury, N. R.;

Dutta, N. K., Structural ensembles reveal intrinsic disorder for the multi-stimuli responsive bio-mimetic protein Rec1-resilin. Sci. Rep. 2015, 5 (1), 10896.

(10) Balu, R.; Mata, J. P.; Knott, R.; Elvin, C. M.; Hill, A. J.; Choudhury, N. R.; Dutta, N. K., Effects of crowding and environment on the evolution of conformational ensembles of the multi-stimuli-responsive intrinsically disordered protein, Rec1-resilin: A small-angle scattering investigation. J. Phys. Chem. B 2016, 120 (27), 6490-6503.

(11) Dutta, N. K.; Choudhury, N. R.; Truong, M. Y.; Kim, M.; Elvin, C. M.; Hill, A. J., Physical approaches for fabrication of organized nanostructure of resilin-mimetic elastic protein rec1-resilin. Biomaterials 2009, 30 (28), 4868-4876.

(12) Truong, M. Y.; Dutta, N. K.; Choudhury, N. R.; Kim, M.; Elvin, C. M.; Hill, A. J.; Thierry, B.; Vasilev, K., A pH-responsive interface derived from resilin-mimetic protein Rec1-resilin. Biomaterials 2010, 31 (15), 4434-4446.

(13) Truong, M. Y.; Dutta, N. K.; Choudhury, N. R.; Kim, M.; Elvin, C. M.; Nairn, K. M.; Hill, A. J., The effect of hydration on molecular chain mobility and the viscoelastic behavior of resilin-mimetic protein-based hydrogels. Biomaterials 2011, 32 (33), 8462-8473.

(14) Mayavan, S.; Dutta, N. K.; Choudhury, N. R.; Kim, M.; Elvin, C. M.; Hill, A. J., Selforganization, interfacial interaction and photophysical properties of gold nanoparticle complexes derived from resilin-mimetic fluorescent protein rec1-resilin. Biomaterials 2011, 32 (11), 2786-2796.

(15) Dutta, N. K.; Choudhury, N. R.; Mayavan, S.; Balu, R.; Whittaker, J. L.; Elvin, C. M.; Hill, A. J., Template directed formation of metal nanoparticles and uses thereof. WO Patent 2014071463 A1, 2014.

(16) Balu, R.; Bourgeois, L.; Elvin, C. M.; Hill, A. J.; Choudhury, N. R.; Dutta, N. K., A multi-responsive intrinsically disordered protein (IDP)-directed green synthesis of fluorescent gold nanoclusters. J. Mater. Chem. B 2015, 3 (32), 6580-6586.

(17) Dutta, N. K.; Choudhury, N. R.; Balu, R.; Elvin, C. M.; Hill, A. J., Formation of subnano metal particles. WO Patent 2015024063 A1, 2015.

(18) Balu, R.; Choudhury, N. R.; Mata, J. P.; de Campo, L.; Rehm, C.; Hill, A. J.; Dutta, N. K., Evolution of the interfacial structure of a catalyst ink with the quality of the dispersing solvent: A contrast variation small-angle and ultra-small-angle neutron scattering Investigation. ACS Appl. Mater. Interfaces 2019, 11 (10), 9934-9946. 
(19) Balu, R.; Knott, R.; Elvin, C. M.; Hill, A. J.; R. Choudhury, N.; Dutta, N. K., A sustainable biomineralization approach for the synthesis of highly fluorescent ultra-small $\mathrm{Pt}$ nanoclusters. Biosensors 2019, 9 (4), 128.

(20) Whittaker, J. L.; Dutta, N. K.; Knott, R.; McPhee, G.; Voelcker, N. H.; Elvin, C.; Hill, A.; Choudhury, N. R., Tunable Thermoresponsiveness of resilin via coassembly with rigid biopolymers. Langmuir 2015, 31 (32), 8882-8891.

(21) Whittaker, J. L.; Dutta, N. K.; Elvin, C. M.; Choudhury, N. R., Fabrication of highly elastic resilin/silk fibroin based hydrogel by rapid photo-crosslinking reaction. J. Mater. Chem. B 2015, 3 (32), 6576-6579.

(22) Hu, X.; Xia, X.-X.; Huang, S.-C.; Qian, Z.-G., Development of adhesive and conductive resilin-based hydrogels for wearable sensors. Biomacromolecules 2019, 20 (9), 3283-3293.

(23) Rattan, S.; Li, L.; Lau, H. K.; Crosby, A. J.; Kiick, K. L., Micromechanical characterization of soft, biopolymeric hydrogels: stiffness, resilience, and failure. Soft Matter 2018, 14 (18), 3478-3489.

(24) Vashi, A. V.; Ramshaw, J. A. M.; Glattauer, V.; Elvin, C. M.; Lyons, R. E.; Werkmeister, J. A., Controlled surface modification of tissue culture polystyrene for selective cell binding using resilin-inspired polypeptides. Biofabrication 2013, 5 (3), 035005.

(25) Dreyer, D. R.; Park, S.; Bielawski, C. W.; Ruoff, R. S., The chemistry of graphene oxide. Chem. Soc. Rev. 2010, 39 (1), 228-240.

(26) Lee, W. C.; Lim, C. H. Y. X.; Shi, H.; Tang, L. A. L.; Wang, Y.; Lim, C. T.; Loh, K. P., Origin of enhanced stem cell growth and differentiation on graphene and graphene oxide. ACS Nano 2011, 5 (9), 7334-7341.

(27) Zhang, Y.; Wu, C.; Gou, S.; Zhang, J., Interactions of graphene and graphene oxide with proteins and peptides. Nanotechnol. Rev. 2013, 2 (1), 27-45.

(28) Balu, R.; Reeder, S.; Knott, R.; Mata, J.; de Campo, L.; Dutta, N. K.; Choudhury, N. R., Tough photocrosslinked silk fibroin/graphene oxide nanocomposite hydrogels. Langmuir 2018, 34 (31), 9238-9251.

(29) Kim, M.; Elvin, C.; Brownlee, A.; Lyons, R., High yield expression of recombinant pro-resilin: Lactose-induced fermentation in E. coli and facile purification. Protein Expression Purif. 2007, 52 (1), 230-236.

(30) Wood, K.; Mata, J. P.; Garvey, C. J.; Wu, C.-M.; Hamilton, W. A.; Abbeywick, P.; Bartlett, D.; Bartsch, F.; Baxter, P.; Booth, N.; Brown, W.; Christoforidis, J.; Clowes, D.; d'Adam, T.; Darmann, F.; Deura, M.; Harrison, S.; Hauser, N.; Horton, G.; Federici, D.; 
Franceschini, F.; Hanson, P.; Imamovic, E.; Imperia, P.; Jones, M.; Kennedy, S.; Kim, S.; Lam, T.; Lee, W. T.; Lesha, M.; Mannicke, D.; Noakes, T.; Olsen, S. R.; Osborn, J. C.; Penny, D.; Perry, M.; Pullen, S. A.; Robinson, R. A.; Schulz, J. C.; Xiong, N.; Gilbert, E. P., QUOKKA, the pinhole small-angle neutron scattering instrument at the OPAL Research Reactor, Australia: design, performance, operation and scientific highlights. J. Appl. Crystallogr. 2018, 51 (2), 294-314.

(31) Rehm, C.; de Campo, L.; Brûlé, A.; Darmann, F.; Bartsch, F.; Berry, A., Design and performance of the variable-wavelength Bonse-Hart ultra-small-angle neutron scattering diffractometer KOOKABURRA at ANSTO. J. Appl. Crystallogr. 2018, 51 (1), 1-8.

(32) Svergun, D. I.; Koch, M. H. J., Small-angle scattering studies of biological macromolecules in solution. Rep. Prog. Phys. 2003, 66 (10), 1735-1782.

(33) Whittaker, J. L.; Balu, R.; Knott, R.; de Campo, L.; Mata, J. P.; Rehm, C.; Hill, A. J.; Dutta, N. K.; Roy Choudhury, N., Structural evolution of photocrosslinked silk fibroin and silk fibroin-based hybrid hydrogels: A small angle and ultra-small angle scattering investigation. Int. J. Biol. Macromol. 2018, 114, 998-1007.

(34) Dorishetty, P.; Balu, R.; Sreekumar, A.; de Campo, L.; Mata, J.; Choudhury, N. R.; Dutta, N. K., Robust and tunable hybrid hydrogels from photocrosslinked soy protein isolate and regenerated silk fibroin. ACS Sustainable Chem. Eng. 2019, 7 (10), 9257-9271.

(35) Dorishetty, P.; Balu, R.; Athukoralalage, S. S.; Greaves, T. L.; Mata, J.; de Campo, L.; Saha, N.; Zannettino, A. C. W.; Dutta, N. K.; Choudhury, N. R., Tunable biomimetic hydrogels from silk fibroin and nanocellulose. ACS Sustainable Chem. Eng. 2020, 8 (6), 2375-2389.

(36) Hunt, J. A.; Chen, R.; van Veen, T.; Bryan, N., Hydrogels for tissue engineering and regenerative medicine. J. Mater. Chem. B 2014, 2 (33), 5319-5338.

(37) Su, R. S. C.; Gill, E. E.; Kim, Y.; Liu, J. C., Characterization of resilin-like proteins with tunable mechanical properties. J. Mech. Behav. Biomed. Mater. 2019, 91, 68-75.

(38) Dhandayuthapani, B.; Yoshida, Y.; Maekawa, T.; Kumar, D. S., Polymeric scaffolds in tissue engineering application: A review. Int. J. Polym. Sci. 2011, 2011, 290602.

(39) Schaefer, D. W.; Agamalian, M. M., Ultra-small-angle neutron scattering: A new tool for materials research. Curr. Opin. Solid State Mater. Sci. 2004, 8 (1), 39-47.

(40) Heller, W. T., Small-angle neutron scattering and contrast variation: a powerful combination for studying biological structures. Acta Crystallogr., Sect. D 2010, 66 (11), 1213-1217. 
(41) Vorobiev, A.; Dennison, A.; Chernyshov, D.; Skrypnychuk, V.; Barbero, D.; Talyzin, A. V., Graphene oxide hydration and solvation: an in situ neutron reflectivity study. Nanoscale 2014, 6 (20), 12151-12156.

(42) Rambo, R. P.; Tainer, J. A., Characterizing flexible and intrinsically unstructured biological macromolecules by SAS using the Porod-Debye law. Biopolymers 2011, 95 (8), 559-571.

(43) Feigin, L. A.; Svergun, D. I., Structure analysis by small-angle X-ray and neutron scattering. Springer US: 2013.

(44) Hammouda, B., A new Guinier-Porod model. J. Appl. Crystallogr. 2010, 43 (4), 716719.

(45) Debye, P.; Anderson, H. R.; Brumberger, H., Scattering by an inhomogeneous solid. II. The correlation function and its application. J. Appl. Phys. 1957, 28 (6), 679-683.

(46) Mildner, D. F. R.; Hall, P. L., Small-angle scattering from porous solids with fractal geometry. J. Phys. D: Appl. Phys. 1986, 19 (8), 1535-1545.

(47) Mallineni, S. S. K.; Shannahan, J.; Raghavendra, A. J.; Rao, A. M.; Brown, J. M.; Podila, R., Biomolecular interactions and biological responses of emerging two-dimensional materials and aromatic amino acid complexes. ACS Appl. Mater. Interfaces 2016, 8 (26), 16604-16611.

(48) Ahearne, M., Introduction to cell-hydrogel mechanosensing. Interface Focus 2014, 4 (2), 20130038.

(49) Engler, A. J.; Sen, S.; Sweeney, H. L.; Discher, D. E., Matrix elasticity directs stem cell lineage specification. Cell 2006, 126 (4), 677-689.

(50) Young, D. A.; Choi, Y. S.; Engler, A. J.; Christman, K. L., Stimulation of adipogenesis of adult adipose-derived stem cells using substrates that mimic the stiffness of adipose tissue. Biomaterials 2013, 34 (34), 8581-8588.

(51) Joon Kwon, H., Chondrogenesis on sulfonate-coated hydrogels is regulated by their mechanical properties. J. Mech. Behav. Biomed. Mater. 2013, 17, 337-346.

(52) Huson, M. G.; Maxwell, J. M., The measurement of resilience with a scanning probe microscope. Polym. Test. 2006, 25 (1), 2-11.

(53) Marsden, A. J.; Papageorgiou, D. G.; Vallés, C.; Liscio, A.; Palermo, V.; Bissett, M. A.; Young, R. J.; Kinloch, I. A., Electrical percolation in graphene-polymer composites. 2D Materials 2018, 5 (3), 032003. 
(54) Solon, J.; Levental, I.; Sengupta, K.; Georges, P. C.; Janmey, P. A., Fibroblast adaptation and stiffness matching to soft elastic substrates. Biophys. J. 2007, 93 (12), 4453 4461 .

(55) Hashemi, E.; Akhavan, O.; Shamsara, M.; Majd, S.A.; Sanati, M.H.; Joupari, M.D.; Farmany, A. Graphene oxide negatively regulates cell cycle in embryonic fibroblast cells. Int. J. Nanomedicine 2020, 15, 6201-6209

(56) Fam, S. Y.; Chee, C. F.; Yong, C. Y.; Ho, K. L.; Mariatulqabtiah, A. R.; Tan, W. S., Stealth coating of nanoparticles in drug-delivery systems. Nanomaterials 2020, 10 (4), 787. 